\title{
Outbreak of Anticonvulsant Intoxication in an Australian City*
}

\author{
J. H. TYRER, $\dagger$ M.D., F.R.C.P., F.R.A.C.P. ; M. J. EADIE, $\ddagger$ M.D., PH.D., F.R.A.C.P. \\ J. M. SUTHERLAND, $\emptyset$ M.D., F.R.C.P.ED., F.R.A.C.P. ; W. D. HOOPER, \| B.SC., A.R.A.C.I.
}

British Medical fournal, 1970, 4, 271-273

\begin{abstract}
Summary: An outbreak of anticonvulsant intoxication occurred in epileptic patients in Australia during 1968-9. All affected patients studied in Brisbane were taking one brand of phenytoin. In $87 \%$ of them the blood phenytoin levels were above the therapeutic range. Reduction of phenytoin dosage relieved the intoxication in all patients. The excipient in the responsible phenytoin capsules had been changed several months before the outbreak, and this change was probably related causally to the altered blood phenytoin concentrations.
\end{abstract}

\section{Introduction}

While anticonvulsant overdosage is accepted as an occasional hazard in the drug treatment of epilepsy, it certainly is not usual to encounter within a period of several months many epileptic patients who have previously taken anticonvulsant therapy without ill effect and who have then almost simultaneously developed manifestations of drug intoxication. Yet such an event occurred in various cities in Australia during 1968 (Balla, 1968; Eadie et al., 1968; Rail, 1968). The present paper recounts an experience of this "epidemic" of anticonvulsant intoxication seen in the City of Brisbane, which draws on the population of south-eastern Queensland (about one million people), and describes preliminary attempts to determine the factors responsible for the outbreak.

\section{History of the Outbreak}

During the Australian autumn (April and May) of 1968 we became aware of several instances of apparent anticonvulsant intoxication in Brisbane. Occasional patients so intoxicated continued to present until mid-1969, though most affected persons were seen before September 1968. In all we saw 51 persons who were affected. Since mid-1969 no instances of anticonvulsant intoxication have been seen which could not be explained in terms of increased dosage of antiepileptic drugs. The disturbance began in most patients during May, June, and July 1968. The month of onset of symptoms in 49 patients is given in Table $I$. Usually patients presented within two to four weeks of their onset of symptoms but occasional patients had manifestations of anticonvulsant intoxication for as long as six to nine months before they were referred.

\section{Clinical Picture}

Many of the affected patients were referred with a diagnosis of possible posterior fossa tumour. Ataxia of gait was present in all patients except for a youth with a spastic diplegia who had never walked and whose ataxia was manifested by inability to remain upright in his wheel chair. One patient, of hysterical personality, spent some weeks in bed before admission because of being unable to stand unsupported. Many patients complained of double vision, and several had periods of vomiting, which often occurred soon

* A preliminary account of this outbreak was given to a meeting of the

Australian Association of Neurologists in May, 1969.
+ Professor of Medicine, University of Queensland.

$\$$ Neurologist, Royal Brisbane Hospital.

Senior Neurologist, Royal Brisbane Hospital.

II Research Chemist, University of Queensland. Medical Professorial Unit of Queensland University, Royal Brisbane
Hospital, Brisbane, Australia. after taking their convulsant drug. Two patients showed unusual features: one developed a schizophrenia-like illness as well as ataxia of gait, spent many weeks in hospital, and, even after the cause of the gait disturbance was diagnosed and treated, continued to show abnormalities of mental functioning; the other patient, who had symptoms compatible with anticonvulsant intoxication for at least some months before admission, showed bilateral pyramidal signs and dystonic movements of her face, limbs, and trunk. Apart from the schizophrenia-like illness, all the above-mentioned abnormalities gradually disappeared when the anticonvulsant dosages were reduced.

In several patients electroencephalograms showed slowing of the mean alpha-rhythm frequency, together with excessive amounts of bilateral slow activity, and when anticonvulsant dosages were reduced the electroencephalograms tended to revert to more normal appearances.

\section{Diagnosis}

The clinical picture of the patients was consistent with the diagnosis of anticonvulsant intoxication, and the response to decreased anticonvulsant therapy tended to support this view. Inquiry showed that in the four weeks preceding the onset of symptoms a change had been prescribed in their dosage of anticonvulsant or other treatment in only six of the 51 affected patients. A few may have varied their dosages at their own whim and been unwilling to admit to so doing, but it seemed improbable that so many epileptics would simultaneously and spontaneously have increased their consumption of anticonvulsants. Therefore a deliberate increase in anticonvulsant consumption did not seem to be an adequate explanation for the outbreak of anticonvulsant intoxication. Consequently, some change in one of the anticonvulsant preparations was suspected as being responsible for the outbreak.

When the anticonvulsant drugs taken by the affected patients (Table II) were considered, it became clear that the only one taken by all patients was the $100-\mathrm{mg}$. phenytoin sodium (diphenylhydantoin) capsules produced by one particular manufacturer. Furthermore, in six patients this was the only medication being taken. As the clinical picture was compatible with phenytoin intoxication the epidemic was probably one of phenytoin overdosage and related to some abnormality in the particular brand of $100-\mathrm{mg}$. phenvtoin sodium capsules being taken by all the affected patients. When phenytoin consumption during intoxication was compared with that after the patients were restabilized to relieve the

TABLE I.-Number of Patients Developing Anticonvulsant Intoxication Monthly During the Period of the "Epidemic"*

\begin{tabular}{c|c|c|c|c|c|c|c|c|c|c|c}
\hline $\begin{array}{c}\text { Feb. } \\
1\end{array}$ & $\underset{0}{\text { Mar. }}$ & \begin{tabular}{c} 
Apr. \\
\hline
\end{tabular} & $\underset{7}{\text { May }}$ & $\begin{array}{c}\text { June } \\
11\end{array}$ & $\begin{array}{c}\text { July } \\
10\end{array}$ & $\begin{array}{c}\text { Aug. } \\
5\end{array}$ & $\begin{array}{c}\text { Sept. } \\
6\end{array}$ & $\begin{array}{c}\text { Oct. } \\
3\end{array}$ & $\begin{array}{c}\text { Nov. } \\
2\end{array}$ & $\begin{array}{c}\text { Dec. } \\
1\end{array}$ & $\begin{array}{c}\text { Jan. } \\
1\end{array}$ \\
\hline
\end{tabular}

* In 2 patients the date of onset of symptoms was indefinite.

TABLE II.-Therapy being Taken by 51 Patients when They Developed Anticonvulsant Intoxication

Drug
Phenytoin $100 \mathrm{mg}$.

Phenytoin $30 \mathrm{mg}$.

Phenobarbitone

Methylphenobarbitone

Primidone

Carbamazepine 
drug intoxication it was found that in two-thirds of the patients it had been necessary to reduce the phenytoin dosage prescribed by $20-40 \%$, and in another one-quarter of the patients by more than $40 \%$.

\section{Blood Phenytoin Concentrations}

That the epidemic of anticonvulsant intoxication was due to phenytoin overdosage was confirmed by measurements of blood phenytoin concentrations performed in 39 of the 51 patients (Table III). The phenytoin assay method developed by Wallace (1966) was used for the estimations. Blood for phenytoin estimation was sometimes taken after anticonvulsant therapy had been stopped, so that the concentrations may not always have been the maximal ones present in indi-

TABLE III.-Blood Phenytoin Concentrations in 39 Patients

\begin{tabular}{|c|c|c|c|c|}
\hline \multicolumn{3}{|c|}{ Phenytoin Concentration ( $\mu \mathrm{g} . / \mathrm{ml}$.) } & Number & Percentage \\
\hline $\begin{array}{c}40-49 \\
30-39 \\
20-29 \\
10-19 \\
0-9\end{array}$ & $\begin{array}{l}\cdots \\
\cdots \\
\cdots \\
\cdots\end{array}$ & $\begin{array}{l}\ldots \\
\cdots \\
\cdots \\
\cdots\end{array}$ & $\begin{array}{r}6 \\
11 \\
17 \\
3 \\
2\end{array}$ & $\left.\begin{array}{c}15 \\
28 \\
44 \\
8 \\
5\end{array}\right\} 87$ \\
\hline
\end{tabular}

vidual patients at the height of intoxication. Nevertheless, in 34 of the 39 patients $(87 \%)$ the phenytoin level was above what is usually regarded as the therapeutic range (10 to 20 $\mu \mathrm{g} . / \mathrm{ml}$.) (Table III). In three patients we had measured blood phenytoin concentrations before intoxication occurred and again during intoxication: levels of $6.5,7.5$, and $12.6 \mu \mathrm{g} . / \mathrm{ml}$, rose to $24.2,33.0$, and $20.4 \mu \mathrm{g} . / \mathrm{ml}$, respectively.

\section{Cause of the Outbreak}

\section{Phenytoin Preparation Responsible}

Once it was realized that the epidemic was one of phenytoin intoxication and that all affected patients were taking the one brand of $100-\mathrm{mg}$. phenytoin sodium capsules, these particular capsules were suspected of containing more than $100 \mathrm{mg}$. of phenytoin sodium. However, using the Wallace (1966) method, assay of the phenytoin content of several capsules from the batches being taken by different patients at the times when they developed drug intoxication showed amounts of phenytoin ranging between 92 and $98 \mathrm{mg}$. per capsule. Clearly the capsules did not contain excess drug. Therefore the less likely possibility that all previous phenytoin sodium capsules produced by the particular manufacturer had contained too little drug was explored. When two of this manufacturer's 100-mg. phenytoin sodium capsules which had been made four years previously and which were being used in a drug trial were analysed they contained 99 and $100 \mathrm{mg}$. of drug, respectively. Thus the fault did not appear to lie in the phenytoin content of the capsules.

It was ascertained from the manufacturer of the suspect $100 \mathrm{mg}$. phenytoin sodium capsules that from November 1967 onward the excipient in this particular strength of phenytoin sodium capsule had been changed from calcium sulphate dihydrate to lactose, and there had been a slight increase in the contents of both magnesium silicate and magnesium stearate in the capsules. No changes had been made in the excipient contained in any other phenytoin preparation produced by this manufacturer. As it might take some weeks for a batch of newly manufactured capsules to come on to the market and reach patients a causal relation between the change in excipient in the capsules and the outbreak of phenytoin intoxication did seem possible. Interestingly, between October and December 1966 the manufacturers had also produced a batch of $100-\mathrm{mg}$. phenytoin sodium capsules which contained lactose as excipient instead of calcium

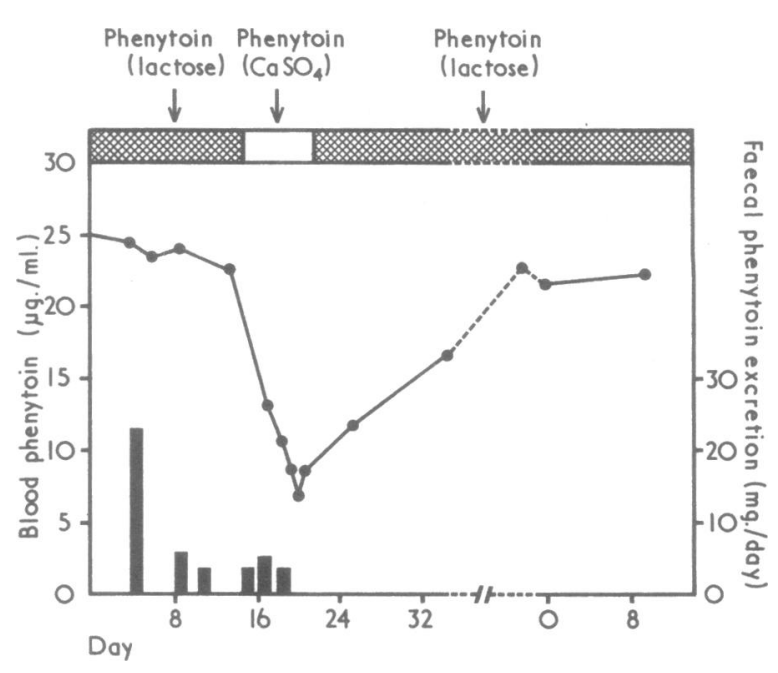

Blood phenytoin concentrations in a patient taking phenytoin (400 mg./day), with excipients respectively as shown (lactose, calcium sulphate, lactose). Vertical columns represent daily faecal excretion of phenytoin when measured.

sulphate, and in mid-1967 we had begun to see an unusual number of cases which were clinically diagnosed as probable phenytoin intoxication, but the outbreak ceased before we were in a position to investigate it.

\section{Effect of Changed Excipient in Capsules}

The above evidence suggests a possible causal relation between the change in excipient and the outbreak of phenytoin intoxication. Direct evidence for such a relation was obtained in one patient (see Chart) in whom serial blood phenytoin concentrations were estimated while his treatment was changed from phenytoin with lactose excipient to phenytoin with calcium sulphate excipient and then back to phenytoin with lactose excipient, there being no significant change in the daily amount of phenytoin ingested at any stage. This patient's blood phenytoin concentration fell rapidly to a quarter of its former value when the phenytoin with calcium sulphate excipient was used instead of phenytoin with lactose excipient. The blood phenytoin concentration rose again when phenytoin (lactose excipient) was reintroduced. The 24-hour faecal phenytoin excretion was measured at the time of the change over of the two preparations. There was no increase in faecal phenytoin loss at the time of the fall in blood phenytoin concentration, which suggested that the decrease in blood phenytoin was not due to increased faecal phenytoin loss. Subsequently serial blood phenytoin concentrations were measured in three further patients who were changed from phenytoin with calcium sulphate excipient to phenytoin with lactose excipient without change in phenytoin dose. In all instances the preparation with lactose excipient produced substantially higher blood phenytoin concentrations (see Table IV).

TABlE IV.-Blood Phenytoin Concentrations when Patients were Taking a Constant Dosage (100 mg. Three or Four Times a Day) of Phenytoin, with Different Excipients

\begin{tabular}{c|c|c}
\hline \multirow{2}{*}{$\begin{array}{c}\text { Case } \\
\text { No. }\end{array}$} & \multicolumn{2}{|c}{ Blood Phenytoin Concentrations ( $\mu \mathrm{g} . / \mathrm{ml})}$. \\
\cline { 2 - 3 } & Phenytoin (Calcium Sulphate Excipient) & Phenytoin (Lactose Excipient) \\
\hline 1 & $3 \cdot 0,3 \cdot 2,3 \cdot 9,3 \cdot 1$ & $7 \cdot 8,8 \cdot 5,12 \cdot 7$ \\
2 & $1.2 \cdot 5,1 \cdot 6$ & $4 \cdot 7,5 \cdot 0,7 \cdot 2,7 \cdot 8$ \\
3 & $1 \cdot 3,1 \cdot 3,1.6$ & $7.5,8 \cdot 1,7 \cdot 5$ \\
\hline
\end{tabular}

\section{Discussion}

Clinical, epidemiological, and chemical evidence showed that a change in the excipient in phenytoin sodium capsules was associated with alterations in blood phenytoin concentrations, and with clinical anticonvulsant intoxication, in a series 
of patients. The mechanism through which the changed excipient exerted its effects did not appear to be an oddity of metabolism restricted to a few patients but seemed to be a common, if not a general, phenomenon among epileptics. This view was supported both by the many instances of anticonvulsant intoxication seen during the epidemic and by the subsequent finding of epileptic patients who were receiving treatment with phenytoin but whose seizures had not been adequately controlled until the approximate time of the epidemic of anticonvulsant intoxication; since that time these patients had very much better or complete control of their epilepsy. Thus though inadequate levels of phenytoin in blood and tissue had been attained previously, in these latter patients, the increased phenytoin concentrations associated with the change of excipient may have improved control of their epilepsy.

Excipients have often been thought of as inert substances present in pharmaceutical preparations merely to allow their manufacture in a convenient form, but from the experience described here excipients may not always be biologically inert. Knowledge of this possibility should deter manufacturers from changing the excipient in their preparations, and should make the physician wary of changing from one brand of a particular drug to another. The theoretical possibility that the excipient in one pharmaceutical preparation might alter the metabolism of another drug administered simultaneously should also be considered.

\section{REFERENCES}

Balla, J. (1968). Medical fournal of Australia, 2, 480.

Eadie, M. J., Sutherland, J. M., and Tyrer, J. H. (1968). Medical fournal

of Australia, 2, 515.

Rail, L. (1968). Medical fournal of Australia, 2, 339.
Wallace, J. E. (1966). Fournal of Forensic Sciences, 11, 552.

\title{
Vascular Complications in Nephrotic Syndrome: Relationship to Steroid Therapy and Accelerated Thromboplastin Generation
}

\author{
A. P. MUKHERJEE, ${ }^{*}$ M.B., M.R.C.P.ED. ; B. H. TOH,* M.B., M.R.A.C.P. ; G. L. CHAN, † F.I.M.L.T. \\ K. S. LAU, $¥$ M.B., M.C.P.A. ; J. C. WHITE, $\$ M.B., F.R.C.PATH.
}

British Medical fournal, 1970, 4, 273-276

\begin{abstract}
Summary: Arterial thrombosis and renal vein thrombosis occurred in two men and one woman, respectively, treated with steroids for the nephrotic syndrome. Raised serum cholesterol occurred in one patient only. Though bleeding, clotting, and prothrombin times, as well as the platelet counts, were normal, the rate of thromboplastin generation was increased in all three patients. Adding heparin to the plasma of one patient slowed the rate, and suggested that the raised rate could be due to removal or suppression of such normal circulating coagulation inhibitors. The thromboplastin generation test seems to be useful in diagnosing and managing such hypercoagulable states, and may help in further investigations of their causes.
\end{abstract}

\section{Introduction}

Vascular complications in patients with nephrotic syndrome are an uncommon but serious problem. Though various pathogenetic mechanisms have been considered for these complications there is little agreement about their role. The present study was undertaken to determine the coagulation mechanism in three patients with occlusive vascular disease complicating the nephrotic syndrome. A series of patients without this complication was also studied, with particular reference to the effects of steroid therapy.

\section{Case 1}

A previously healthy 24-year-old Chinese man was admitted to hospital with puffiness of face and swelling of legs. Clinical examination and laboratory investigations showed features of nephrotic syndrome. He had low plasma protein, $3.5 \mathrm{~g} . / 100 \mathrm{ml}$; albumin, $0.65 \mathrm{~g} . / 100 \mathrm{ml}$; and serum cholesterol, $350 \mathrm{mg} . / 100 \mathrm{ml}$. Daily urinary protein excretion ranged from 5.3 to $13.0 \mathrm{~g}$. Bleeding and venous clotting times were normal; lupus erythematosus (L.E.) cell tests were negative. Percutaneous renal biopsy showed

\footnotetext{
- Lecturer in Medicine.

† Laboratory Assistant, Superscale.

¥ Professor and Head of Department of Pathology.

Senior Lecturer in Pathology.

Faculty of Medicine, University of Malaya, Kuala L.umpur.
}

features of proliferative glomerulonephritis. His oedema improved on $60 \mathrm{mg}$. of prednisolone daily but reoccurred three weeks after discharge because he neglected to take his tablets. After another three weeks in hospital he was discharged on $45 \mathrm{mg}$. of prednisolone daily. The erythrocyte sedimentation rate (E.S.R.) remained raised throughout, $88-116 \mathrm{~mm}$. in first hour (Westergren).

Two months later he was readmitted with femoral artery thrombosis. Right midthigh amputation was performed, and on examination the femoral artery and its branches were occluded. There was medial hyperplasia and intimal proliferation, but no evidence of arteritis or any atherosclerosis.

On coagulation study platelets were normal in number, morphology, adhesiveness, and aggregation; fibrinogen levels, prothrombin time, and thrombotest were also normal. The thromboplastin generation test (Biggs and Douglas, 1953), however, showed an accelerated pattern on two occasions (see Table and Fig. 1). The patient's plasma, and particularly the serum, produced an intermediate degree of acceleration when mixed with normal serum or plasma, respectively. At this time he had two weakly positive L.E. cell tests out of four, but subsequent tests had been negative. Complete clinical remission has since occurred with immunosuppressive therapy.

\section{Case 2}

A 35-year-old Chinese was admitted to hospital for swelling of the legs. He had had a similar illness when he was 10 years old. Features of the nephrotic syndrome were found on clinical examination and laboratory investigations. The serum cholesterol was very high at $950 \mathrm{mg} . / 100 \mathrm{ml}$. Total serum proteins were $4.2 \mathrm{~g} . / 100 \mathrm{ml}$. and albumin $2.0 \mathrm{~g} . / 100 \mathrm{ml}$. The daily urinary protein varied from 5 to $10 \mathrm{~g}$. The bleeding, clotting, and prothrombin times were normal; L.E. cell tests were negative on three occasions. No specific changes by light microscopy were seen in the renal biopsy specimen, and the nephrotic syndrome of "minimal change" type (Habib et al., 1961) was diagnosed. At discharge the patient was on $45 \mathrm{mg}$. of prednisolone daily. After being sympton-free for 10 months he was readmitted for exacerbation of the nephrotic syndrome. During this admission he developed substernal chest pain due to anterior myocardial infarction. Serum cholesterol ranged from 1,300 to $1,900 \mathrm{mg}$./100 ml. Coagulation studies showed no platelet abnormality; plasma fibrinogen levels, prothrombin time, and thrombotest were normal. There was, however, definite acceleration of thromboplastin generation on three occasions over a three-month period (see Table and Fig. 